\title{
A Profile of Support Group Use and Need among Middle-aged and Older Adults with Multiple Sclerosis
}

\author{
Authors: $\quad$ Marcia L. Finlayson, PhD, OT (C), OTR/L [Corresponding author] \\ Professor \\ Department of Occupational Therapy \\ University of Illinois at Chicago \\ 1919 W. Taylor Street (MC 811) \\ Chicago, IL, 60612 \\ Chi C. Cho, MS \\ PhD Candidate - Epidemiology and Biostatics, School of Public Health and \\ Research Assistant, Department of Occupational Therapy \\ University of Illinois at Chicago \\ 1919 W. Taylor Street (MC 811) \\ Chicago, IL, 60612
}

Acknowledgements: Special thanks are extended to members of the research team who were involved in collecting the data used in the preparation of this paper: Toni Van Dendend (Project Coordinator), Eynat Shevil, Jennifer Garcia, Danielle Lemon, Terri Boss, and Aimee Rabidoux (Research Assistants).

Source of Funding: This study is supported by the National Multiple Sclerosis Society through Health Care Delivery and Policy Research Contract \#HC049, awarded to Dr. Finlayson. The information presented in this paper does not necessarily reflect the position, ideas or opinions of the National Multiple Sclerosis Society.

Conflict of Interest: None 


\begin{abstract}
This study compared middle-aged and older adults with multiple sclerosis ( $\mathrm{N}=1,275)$ according to their use of support groups and identified factors associated with perceived need. Over 64.6\% ( $n=824$ ) of participants had attended a MS support group meeting at least once. Individuals who had never attended a group were more likely to reside in urban or suburban communities, report lower symptom interference, and fewer activity limitations. Women, individuals without a helper, and people with greater symptom interference were more likely to perceive a need for a support group. Findings raise questions for professionals involved in developing and implementing multiple sclerosis support groups.
\end{abstract}

Key Words: Self-help group, social support, coping, chronic disease, self-management 
Multiple sclerosis is a chronic, degenerative disease of the central nervous system that can contribute to significant functional losses and disability (Khan \& Pallant, 2007; Nortvedt, Riise, Myhr, \& Nyland, 2000; Paltamaa, Sarasoja, Leskinen, Wikstrom, \& Malkia, 2008). The progressive yet unpredictable nature of the disease has been identified as a major stressor for people with MS (Gulick, 2001; Kroencke \& Denney, 1999). In response, many health care professionals encourage people with MS to participate in support groups to learn more about the disease, obtain support from peers, and enhance their ability to cope with and manage the consequences of the disease (Davison, Pennebaker, \& Dickerson, 2000; Peters, Somerset, Campbell, \& Sharp, 2003; Uccelli, Mohr, Battalia, Zagami, \& Mohr, 2004).

Support groups are sometimes distinguished from self-help groups by virtue of their leadership (professional versus peer) (Kessler \& Zhao, 1997; Uccelli et al., 2004; VandenBos, 2007), although others use these terms interchangeably (Davison et al., 2000). Regardless of their label and leadership, these groups share common goals: to provide education and information that helps people cope with their disease through modeling and social persuasion, facilitate social interactions and networking, and encourage group advocacy (Davison et al., 2000; Gottlieb, 2000; Peters et al., 2003; Uccelli et al., 2004; VandenBos, 2007). For the purpose of this paper, the term support groups will be used to refer to both peer and professionally lead groups that are held in a face-to-face format.

The use and value of support groups has been discussed for older adults (Gottlieb, 2000), women with breast cancer (Stang \& Mittelmark, 2010), men with HIV (Walch, Roetzer, \& Minnett, 2006), and individuals dealing with a wide range of specific diseases or life situations (e.g., substance abuse, eating disorders, parenting, grief, mental illness, domestic abuse) (Davison et al., 2000; Kessler \& Zhao, 1997). Support group attendance is higher among 
individuals whose experiences are socially stigmatizing, and whose disabilities are disfiguring, require costly medications, or are accompanied by higher risk of death (Davison et al., 2000). Support group attendance has been correlated with a recent physician contact, having a less supportive social network (Kessler \& Zhao, 1997), and in some cases, higher levels of education (Stevens \& Duttlinger, 1998; Walch et al., 2006).

Very little has been documented about the use of or perceived need for support groups among people with MS. Little is known about the proportion of people who attend these groups, their distinguishing characteristics, or whether they perceive the groups as meeting their needs. It is also unclear whether there are non-attendees who perceive themselves as needing the information and resources of a support group. An extensive search of the literature uncovered only two studies that directly address these issues among people with MS (Peters et al., 2003; Uccelli et al., 2004).

Peters and colleagues (Peters et al., 2003) focused on attendance at and perceived helpfulness of MS support groups in England and Scotland. They found that 43\% (n=136) of 318 survey respondents had attended a support group at some point since their diagnosis. Only three variables were associated with attendance in multivariate analyses: being middle aged (5564 years of age), having contact with a health care professional in the past 12 months, and perceptions of access to MS-related information. Factors not associated were employment status, length of time since diagnosis, disease course, physical functioning, use of selftreatments, and social functioning.

Uccelli et al. (2004) examined the efficacy of peer support groups among 42 people with MS in Italy who were primarily female, married, and ambulatory. The manualized program did not produce significant improvements in quality of life or depression for the sample as a whole. 
In stratified post-hoc analyses, individuals with lower baseline quality of life were found to have experienced greater improvements ( $\mathrm{p}=0.017)$, as were individuals with lower (worse) baseline levels of depression ( $\mathrm{p}=0.020)$. Participants with a high (positive) baseline mental health scores actually showed worsening $(\mathrm{p}=0.048)$. The findings suggest that the benefits of attending support groups are not consistent across all people with MS, and that attendance for some people may be associated with worse mental health.

Despite the value of these two studies in helping to understand the use of MS support groups, much still needs to be learned given the prevalence of support groups and the human and financial resources allocated to develop and maintain them. It is important to understand who attends support groups, as well as who stops attending and why. In addition, it is also important to understand the characteristics of individuals who perceive that their needs for support groups are unmet, as this knowledge can guide health care professionals and not-for-profit agencies offering support groups as they consider recruitment and retention efforts. Need is a complex phenomenon that can arise from several sources (Bradshaw, 1994; Finlayson, 2006; Schriner \& Fawcett, 1988). This literature suggests that unmet need for support groups may arise from (a) having never attended a support group but acknowledging need for one, (b) having previously attended a support group and acknowledging current need, or (c) reporting that current support group attendance is important or very important to health and well-being, but experiencing no or limited satisfaction with current participation.

In the context of comprehensive MS care, support groups can be viewed as a healthrelated service. According to the Andersen-Newman Model of Health Care Utilization (Andersen \& Newman, 1973), there are factors that predispose an individual to use health services (e.g., being female, older and having more education), factors that enable service use 
(e.g., access to transportation, geographical proximity to services), and factors that lead someone to need services (e.g., poorer health, greater disability). This model provides a useful guide to conceptualize the need for and use of MS support groups, and therefore was used to guide question development and analytic decisions. The specific aims of this descriptive, exploratory study were:

1. To compare the descriptive profiles of individuals with MS by their use of support groups (i.e., non-users, recent users, former users), and

2. To identify the factors associated with unmet need for MS support groups.

\section{Methods}

The current analysis uses data from a large cross-sectional, descriptive study of middleaged and older adults with MS that focused on their unmet health-related service needs and the factors associated with those needs. The study and all of its procedures were approved by the Institutional Review Board of the University of Illinois at Chicago. Support groups were one of 22 services addressed in the study. The study was reviewed and approved by the human subjects’ protection committee of the authors’ university.

Sample: Several methods (e.g. direct mailing, distribution of flyers, consumer newsletter advertising) were used to recruit people with MS who were 45 years of age or older and who lived in Minnesota, Wisconsin, Illinois, Indiana and Michigan, USA. A total of 2,277 volunteers returned a form or telephoned the study office to indicate their willingness to be contacted for an interview. Because the primary focus of the study was on older adults with MS, all of the 779 volunteers aged 65 years and older were contacted for an interview, and 725 participated. For the 45-64 year old group, 585 volunteers were randomly selected from the pool of 1,498, and 557 actually completed the interview. Reasons for non-completion of the interviews for both age 
groups included cognitive impairment, refusal at time of contact, and inability to locate. A total of 1,282 people were interviewed. Of these, 1,275 provided the data about their support group use and therefore constituted the sample for the analyses reported in this paper.

Data Collection and Measures: The structured telephone interview guide was administered by five trained interviewers. The average interview was 42 minutes in length. Items on the interview guide were selected based on findings from a series of initial focus groups (Finlayson, Van Denend, \& Shevil, 2003) and previous studies of the health service needs of older adults and/or people with MS (Chipperfield, Havens, \& Doig, 1997; Fillenbaum, 1988; Finlayson \& Wiebe, 1998; Kersten et al., 2000; Wiebe, Finlayson, \& Payne, 1998). Support groups were one of 22 services addressed during the interview.

Dependent variable: For each service addressed, participants were asked the same pattern of questions. First, they were asked: "Have you ever used [name of service] specifically because of your MS, its symptoms or its consequences?” If the answer was affirmative, they were then asked: "When was the last time you used [service]?” and "Are you still using [service]?” If participants responded affirmatively to the latter of these two questions, they were asked about the frequency of use, the importance of the service to their overall health and wellbeing, and how satisfied they were with the services they were receiving.

To address the first study aim, participants' responses from the “ever use” and "last use” questions were combined to create a 4-level variable. The four categories were: “attended a support group within the past year”, “attended a support group 1 to 3 years ago”, “attended a support group more than 3 years ago”, and “never attended a support group”.

If participants reported never having used the service or not currently using it, they were asked whether they thought that they needed the service. For individuals who were not clear 
what the service entailed, standard explanations were read to facilitate accurate responses. To address the second study aim, a dichotomous variable was constructed (needs met, needs unmet). Individuals whose support group needs were unmet included those who reported: (a) never attending a support group but needing one, (b) previously attending a support group and needing to return, or (c) attending a group but perceiving the group did not meet their needs (i.e., there was a discrepancy between the importance of the group and satisfaction with participation). It was assumed that the support group needs of individuals not fitting into one of these three groupings were met.

Independent variables: The covariates for both analyses were chosen from the available survey items using the Andersen-Newman Model of Health Service Utilization. The same covariates were used in both analyses. Predisposing characteristics included age (continuous), sex and education (high school or less, more than high school). The enabling factors included means of transportation (drive self, informal [family or friend drive], formal [public transit, taxi, disability transit]), type of community (primarily urban/suburban versus small town/rural) and marital status (married/partnered, not married/not partnered). Need factors included availability of a helper (yes, no), living arrangement (live alone, live with others), degree of interference from MS symptoms (very minimal, minimal, moderate, severe), MS status in the past year (stable, improving, deteriorating, variable), degree of ADL limitations and degree of IADL limitations.

The ADL and IADL measures were both derived variables. Participants were asked about the amount of assistance they needed with 11 ADL and then categorized as follows: none, minimal (at least some assistance with 2 to 4 tasks), moderate (at least some assistance with 5 to 10 tasks), and maximal (sometimes or always needs assistance with 11 tasks). The variable for 
degree of IADL limitations was based on responses to 7 activities. Participants were categorized as follows: very minimal limitation (some assistance with 3 or fewer tasks), minimal limitation (some assistance with all 7 tasks), moderate limitation (always needs assistance with 2 to 3 tasks plus some assistance with remaining tasks), and maximum limitation (always needs assistance with at least 4 tasks plus some assistance with remaining tasks).

Analysis: Data were entered into SPSS DataBuilder and then imported into SAS 9.1 for analysis. A preliminary analysis was performed to identify any potential data entry errors. Questionable values were checked and corrected against the raw data on hard copy interview guides.

Aim \#1: Although the 4-level variable constructed to capture service use is inherently ordinal in nature, a proportional odds model was not used for the analysis because the variable failed to meet the proportionality assumption. Instead, a multinomial regression was used. This model is a special form of logistic regression that is appropriate for outcomes that have more than two categories (Agresti, 2002). In our analysis, we used "never attended a support group" as the reference category to which the other three categories were compared (i.e., attended $<1$ year, attended 1 to 3 years ago, attended $>3$ years ago). While all levels of the outcome are modeled simultaneously in a multinomial regression, the estimates produced also allow for any two levels of the outcome to be compared independently. The process for making these additional comparisons involves subtracting one estimate from another and exponentiating the result to obtain an odds ratio (See note 2 on Table 2 for a specific example).

Aim \#2: To address the second study aim, a logistic regression model was used given the dichotomous outcome (needs met, needs unmet) (Agresti, 2002). 
Modeling process for both Aims: Model selection was performed using an ordered block scheme, where the ordering was defined by the three types of characteristics (i.e., predisposing, enabling and need). Within each block, the stepwise selection method was used to select the effects that satisfied the p-value criteria of 0.05 for both entry and remaining in the model. For subsequent blocks, the variable selection was conditional on the significant effects found in the preceding blocks. Using this model selection scheme, the final model may include effects that have type I error of greater than 0.05 .

Multicollinearity amongst the variables was assessed using the variance inflation factor. Results did not indicate any potential problems. In the final model, the goodness of fit tests for the multinomial model were performed using the Deviance $(\mathrm{p}=.5333)$ and Pearson $(\mathrm{p}=.7686)$ statistics. No problems with the model fit were identified. The Hosmer-Lemshow's test was used to test the goodness of fit of the logistic model and resulted in a p-value of 0.9367 , which indicated that the model fit well.

\section{Results}

General Sample Description: The average age of the 1,275 respondents was 63.8 years $(S D=9.4)$. Across the sample, $76.1 \%$ were female. Overall, participants tended to be welleducated, married, and able to move around in the community on their own or with the help of family or friends rather than having to use formal transportation programs. They were nearly equally divided between urban/suburban and small town/rural settings. On average, they had received their diagnosis 20.1 years $(S D=11.49)$ prior to the interview, although they reported having lived with the symptoms of MS for an average of 28.2 years $(S D=13.0)$. Just over onethird (34.0\%) of the participants reported that their MS status was deteriorating. 
Aim \#1 - Support Group Use: Over 64.6\% (n=824) of the sample indicated that they had attended a MS support group meeting at least once since their diagnosis. Nearly $40 \%$ of individuals ( $\mathrm{n}=389$ ) indicated that they had attended a meeting within the year prior to the interview, while another $13.0 \%(\mathrm{n}=108)$ attended a group at some point within the past one to three years. The remaining 39.7\% $(n=327)$ reported attending a support group more than three years ago. At the bivariate level, variables that differentiated participants by time since last support group attendance included degree of symptom interference ( $\mathrm{p}=.0046)$, degree of ADL limitations $(\mathrm{p}<.0001)$, degree of IADL limitation $(\mathrm{p}<.0001)$, age $(\mathrm{p}=.0089)$, and years since diagnosis $(\mathrm{p}<.0001)$. See Table 1.

$<$ Insert Table 1>

The final multinomial regression model examining the factors associated with how recently respondents had attended a MS support group use is summarized in Table 2. For the dependent variable, the "never attended" group is the reference category for all of the comparisons presented in the table. The additional comparisons (e.g., attended $<1$ year ago versus $>3$ years ago) reported below were calculated using the process described in note 2 on Table 2.

Overall, age was found to be a significant predisposing factor $(\mathrm{p}=.0020)$. For every year increase in age, participants were less likely to have attended a support group in the past year compared to people who had never attended a group (OR=0.97). Age also differentiated those participants who had attended in the past year from those who had attended more than three years ago $(\mathrm{OR}=0.97)$.

After controlling for age, the only enabling factor remaining in the model was the type of community in which participants lived. However, after accounting for need factors in the model, 
the significance was only borderline $(\mathrm{p}=0.051)$. Results indicate that people residing in a small town or rural area were 1.45 times more likely to have attended a support group within the past year than to have never attended a support group $(\mathrm{p}=.0093)$.

After controlling for the predisposing and enabling factors, IADL limitations $(\mathrm{p}<.0001)$ was only need factor significantly associated with how recently participants had attended a support group. Because of the 4-level dependent variable, there are a possible 36 comparisons (odds ratios) when examining a 4-level independent variable $\left(4{ }_{c} 2 \times 4 c 2\right)$ such as IADL. Nine of these comparisons are presented in Table 2. Across all possible comparisons, those that were significant indicate that participants with maximal IADL limitations were more likely to have attended a MS support group at any point (i.e., < 1 year [OR=1.78], 1 to 3 years [OR=3.49], > 3 years [OR=2.09]) compared to participants with very minimal IADL limitations (reference group for this independent variable). In addition, participants with minimal or moderate IADL limitations were more likely to have attended a MS support group within the past 3 years (i.e., < 1 year or 1 to 3 years) compared to people with very minimal limitations who have either never attended or attended more than 3 years ago. However, people with maximal IADL limitations were more likely to have attended a support group more than 3 years ago compared to participants with minimal or moderate IADL limitations. These latter individuals were more likely to have attended in the past year.

$<$ Insert Table 3>

Aim \#2 - Support Group Need: Of the 451 participants who had never attended a MS support group meeting, $83.6 \%(n=377)$ did not perceive that they needed to do so. In total, 239 (18.7\%) individuals reported unmet need for a support group (Figure 1). Across these individuals, the majority were former support group users $(n=110)$. These individuals were 
primarily female (81.8\%), with an average age of 63 years ( $\mathrm{SD}=9.0)$. They had been experiencing MS symptoms for an average of 28 years ( $\mathrm{SD}=12.7)$, and were experiencing high levels of symptom interference, ADL limitation, and IADL limitation. Fourteen percent were widowed.

The second largest group of individuals reporting unmet need for support groups had never attended a group but thought that they needed to do so $(n=49)$. Only 30 individuals had a discrepancy between the importance they placed on attending the support group and the satisfaction they reported with the group they attended (i.e., very important/satisfied or not satisfied; important/not satisfied) (Figure 1).

$<$ Insert Figure 1 $>$

The final logistic regression model found that one predisposing factor (gender) and two need factors (presence of helper and interference of MS symptoms) were associated with unmet need for MS support groups (see Table 3). No enabling factors remained in the final model. $<$ Insert Table 3 here $>$

Women were 1.56 times more likely than men to experience an unmet need for MS support group ( $\mathrm{p}=.0163)$. In the initial model selection block, level of education was found to be a significant effect. However, after adjusting for the needs factors, education was no longer associated with unmet need ( $\mathrm{p}=.0773)$.

Participants without a helper available were 3.39 times more likely to identify MS support group as an unmet need ( $\mathrm{p}=.0056)$. The degree of interference of MS symptoms was also significantly associated with unmet need $(\mathrm{p}<.0001)$. Compared to participants who experienced very minimal symptoms interference, all other groups were significantly more likely to express unmet need. Participants with severe, moderate and minimal symptoms interference 
were 1.80, 1.82 and 3.51 times more likely to have unmet need compared to those who experienced only very minimal interference from their symptoms, respectively. See Table 3.

\section{Discussion}

People with MS are often encouraged by health care professionals to participate in support groups. MS Societies around the world commit significant human and financial resources to the organization, implementation and maintenance of these groups. Yet, relatively little has been documented about MS support groups, who uses them (and whether their needs are met), who stops using them, and who does not attend a support group but perceives a need to participate in one. Therefore, this study was designed to extend current knowledge (Peters et al., 2003; Uccelli et al., 2004) by examining the use of support groups among middle-aged and older adults with MS and identifying the factors associated with unmet need for MS support groups.

The majority of participants in this study had attended a MS support group at some point since their diagnosis $(64.6 \%, n=824)$, a rate $21 \%$ higher than reported by Peters and colleagues (Peters et al., 2003) in the UK. This difference may be an artifact of the current study's focus on individuals aging with MS. Nevertheless, over half of our participants reported that it had been over a year since they had attended a support group and for the majority of these people, it had been over three years. Peters and colleagues did not report data on the length of time since the last support group attended, but reported that $20 \%$ of their participants did not find the last meeting attended helpful. Together with findings from Peters et al., our findings raise questions about the fluidity of support group participation, what people with MS expect to get out of support groups, and the extent to which their expectations match their actual experiences. 
According to the literature, support groups tend to serve multiple functions (Davison et al., 2000; Gottlieb, 2000; Peters et al., 2003; Uccelli et al., 2004; VandenBos, 2007). For example, groups often offer disease and health-related knowledge, peer support, and opportunities to learn about coping strategies and available resources. Given the variable nature of MS, it is possible that the support group to which a person has access may not focus on the types of information that best match his/her needs, and this discrepancy may lead to a sense of dissatisfaction and a decision to stop attending. Perhaps the fluidity of participation influences the types of issues addressed within a group at a given point, which in turn, influences the match between a person's needs and the issues being addressed in the group attended. While access to transportation or geographical location may make it possible for some individuals to "shop around” for a support group that best addresses their needs, not all individuals have this luxury. These issues were not explored as part of our study, but would be valuable topics to address in future research.

According to the Andersen-Newman Model, the use of support groups was expected to be influenced by age, gender, transportation, and variables capturing levels of disability. In fact, age was an important factor related to use, with younger people more likely to have attended more recently. Given that the age distribution in this study was 45 to 90 , this finding may reflect a time in the disease process when some individuals are transitioning to a secondary progressive form of the disease (Confavreux \& Vukusic, 2006), experiencing new or worsening symptoms, and therefore seeking new information and support. Surprisingly, gender was not associated with support group use despite previous findings that men are generally less likely to participate in these types of programs (Davison et al., 2000; Kessler \& Zhao, 1997). We view the finding as 
a positive one - it would be unfortunate if there were systematic gender-related differences in the use of support groups given the broad functions they can serve.

Although we did not find that transportation was associated with support group use, type of community was. Individuals who reported living in small towns or rural areas were more likely than those living in urban and suburban areas to have recently attended a support group meeting. In many ways, this finding is counterintuitive since on the basis of population density, urban and suburban areas would be expected to have more options for support groups to attend. It may be that support groups in smaller communities are easier to access or that they have some feature that keeps people attending (e.g., existing relationships, opportunities to develop closer connections). It may also be possible that MS support groups also enable persons to meet a broader array of social needs, particularly a sense of belonging within their community. Both of these potential explanations are worth exploring in future research.

As expected, disability factors played a significant role in support group attendance, and how recently individuals had attended. Although our disability-related findings were consistent with the Andersen-Newman model, they were not consistent with the work of Peters et al (2003). The difference is most likely a function of the specific questions asked in each study, but may also be related to differences in measurement (e.g., IADL limitations versus physical functioning).

We found that individuals with maximal IADL limitations were more likely to have attended a support group overall, and individuals who experienced mid-level limitations were more likely to have recently attended a group. Perhaps individuals with the least disability either use other strategies to address their challenges on their own, or receive little or no encouragement from health care professionals to attend MS support groups. It may be that 
persons with minimal disability avoid attending MS support groups because they are afraid of seeing others with greater disability and having to face the possibility of what could happen in their future. This possibility could explain why individuals with positive baseline mental health scores actually demonstrated worsening after attending the support groups in Uccelli's study (Uccelli et al., 2004).

For individuals with greater disability, getting to support groups may be more difficult and therefore their attendance is less recent. This interpretation is consistent with our finding that individuals with greatest symptom inference were more likely to perceive an unmet need for a support group. It is also consistent with the extensive literature on the transportation problems of people with disabilities (Denson, 2000; Manthorpe et al., 2006; Rimmer, Wang, \& Smith, 2008), suggesting that symptom interference may function as a proxy for transportation difficulties in our model.

A third potential explanation for our disability-related findings may be that individuals start attending support groups to obtain specific information and resources, or to meet other individuals with MS. Once the information is obtained, an individual does not need to continue attending. Similarly, it may be that once the initial social contacts are made, individuals may prefer to develop and maintain relationships outside of the structure of the group. Should future research support these explanations, it would challenge the generally held assumption, one that is held by many health professionals, that people with MS should attend support groups on a regular and on-going basis.

Greater levels of disability were also associated with a greater likelihood of reporting unmet need in our study. Although we were unable to probe why participants thought they needed a support group, their profiles suggested that they may be at greater risk for social 
isolation (e.g., no helper, greater symptom interference in daily life). Perhaps they perceived support groups as having the potential for providing opportunities for socializing and social support. Women were more likely than men to report unmet need, which may reflect women's greater affiliation for these types of groups (Davison et al., 2000; Kessler \& Zhao, 1997).

Surprisingly, unmet need for support groups was not associated with type of community or transportation. Given research on the differences in MS-related service access between urban and rural communities (Buchanan et al., 2006b; Buchanan et al., 2006a; Buchanan, Zhu, \& James, 2007), we assumed that individuals in rural areas would have less access to support groups, and therefore report greater need for them. We also assumed that fewer transportation options in small towns and rural areas would make it more difficult for people to get to support groups, and thus, reduce their participation, and increase their need. Given that these variables were not in the model, it may be that small town/rural participants obtain adequate support through other mechanisms, informal transportation options are readily available, and/or those living in small towns/rural communities are, in general, more resilient. All of these explanations have some degree of support in the literature on rural health and social support issues (Clark \& Leipert, 2007; Gerrard, Kulig, \& Nowatzki, 2004; Paluck, Allerdings, Kealy, \& Dorgan, 2006). Despite the new knowledge gained through this study, it is limited by several factors. First, the sample was comprised of individuals who had been living with MS for a long period of time. Their use of and need for MS support groups may be quite different than younger individuals and/or those who are newly diagnosed. The study is also limited by not having access to narrative data which would have provided a richer and more in-depth understanding of people’s choices to attend or not attend groups, and their perceived unmet needs. For this reason, mixed methods approaches would be valuable in future studies of this topic. Finally, we did not 
have information about the location of available support groups in relation to participants' residences, which would have provided additional opportunities to examine the role of geographical access in support group use and need. Including this information in future studies would add an important dimension to our understanding of support group use and need.

\section{Conclusion}

Support groups can play an important role in the lives of individuals who participate in them by providing opportunities to build friendships and relationships, learn new ways of coping with chronic disease, and gain access to resources that otherwise may remain untapped. Findings indicated that age, community type, and extent of IADL disability influenced how recently a support group had been attended, while gender, being without a helper, and extent of symptom interference influenced the likelihood of reporting unmet need for a support group. These findings suggest that health care professionals who are starting and attempting to maintain support groups must be familiar with potential participants, particularly the extent to which MS symptoms and associated limitations are affecting them. This knowledge may facilitate recruitment and retention strategies, and choice of location, facilities, and group activities and discussion topics. Findings also point to the need to understand what people with MS expect to get out of support group attendance so that their current and on-going needs can be met effectively. 


\section{Reference List}

Agresti, A. (2002). Categorical Data Analysis. (2nd edition ed.) New York: Wiley.

Andersen, R. \& Newman, J. F. (1973). Societal and individual determinants of medical care utilization in the United States. Milbank Memorial Fund Quarterly - Health and Society, 51, 95-124.

Bradshaw, J. (1994). The conceptualization and measurement of need. In J.Popay \& G. Williams (Eds.), Researching the people's health (first ed., pp. 45-57). London and New York: Routledge.

Buchanan, R. J., Schiffer, R., Wang, S., Stuifbergen, A., Chakravorty, B., Zhu, L. et al. (2006a). Satisfaction with mental health care among people with multiple sclerosis in urban and rural areas. Psychiatric Services., 57, 1206-1209.

Buchanan, R. J., Wang, S., Stuifbergen, A., Chakravorty, B. J., Zhu, L., \& Kim, M. (2006b). Urban/rural differences in the use of physician services by people with multiple sclerosis. Neurorehabilitation.21(3):177-87.

Buchanan, R. J., Zhu, L., \& James, W. (2007). Urban/rural differences in health insurance coverage among people with multiple sclerosis. DISABIL REHABIL, 29, 1890-1898.

Chipperfield, J. G., Havens, B., \& Doig, W. (1997). Method and description of the Aging in Manitoba Project: A 20-year longitudinal study. Canadian Journal of Aging, 16, 606625.

Clark, K. J. \& Leipert, B. D. (2007). Strengthening and sustaining social supports for rural elders. Online Journal of Rural Nursing \& Health Care, 7, 13-26.

Confavreux, C. \& Vukusic, S. (2006). Age at disability milestones in multiple sclerosis. Brain, 129, 3-605.

Davison, K., Pennebaker, J., \& Dickerson, S. (2000). Who talks? The social psychology of illness support groups. American Psychologist, 55, 205-217.

Denson, C. R. (2000). Public sector transportation for people with disabilities: a satisfaction survey. Journal of Rehabilitation, 66, 29-37.

Fillenbaum, G. G. (1988). Multidimensional functional assessment of older adults: The Duke Older Americans Resources and Services procedures. Hillsdale, NJ: Lawrence Erlbaum Associates.

Finlayson, M., Van Denend, T., \& Shevil, E. (2003). Multiple perspectives of the health service need, use and variability among older adults with multiple sclerosis. Occupational Therapy in Health Care, 17, 5-25. 
Finlayson, M. (2006). Assessing Need for Services. In G.Kielhofner (Ed.), Scholarship In Occupational Therapy: Methods Of Inquiry For Enhancing Practice. (pp. 591-606). Philadelphia, PA: FA Davis.

Finlayson, M. \& Wiebe, J. (1998). Social Action and IFS Survey Report: Manitoba Division. Toronto, ON: Multiple Sclerosis Society of Canada.

Gerrard, N., Kulig, J., \& Nowatzki, N. (2004). What doesn't kill you makes you stronger: determinants of stress resiliency in rural people of Saskatchewan, Canada. Journal of Rural Health, 20, 59-66.

Gottlieb, B. (2000). Self-help, mutual aid, and support groups among older adults. Canadian Journal on Aging, 19, 58-74.

Gulick, E. E. (2001). Emotional distress and activities of daily living functioning in persons with multiple sclerosis. Nursing Research., 50, 147-154.

Kersten, P., McLellan, D. L., Gross-Paju, K., Grigoriadis, N., Bencivenga, R., Beneton, C. et al. (2000). A questionnaire assessment of unmet needs for rehabilitation services and resources for people with multiple sclerosis: Results from a pilot survey in five European countries. Clinical Rehabilitation, 14, 42-49.

Kessler, K. D. M. \& Zhao, S. (1997). Patterns and correlates of self-help group membership in the United States. Social Policy, 27, 27-37.

Khan, F. \& Pallant, J. F. (2007). Use of International Classification of Functioning, Disability and Health (ICF) to describe patient-reported disability in multiple sclerosis and identification of relevant environmental factors. Journal of Rehabilitation Medicine, 39, 63-70.

Kroencke, D. C. \& Denney, D. R. (1999). Stress and coping in multiple sclerosis: exacerbation, remission and chronic subgroups. Multiple Sclerosis., 5, 89-93.

Manthorpe, J., Cornes, M., Rapaport, J., Moriarty, J., Bright, L., Clough, R. et al. (2006). Commissioning community well-being: focus on older people and transport. Journal of Integrated Care, 14, 28-37.

Nortvedt, M. W., Riise, T., Myhr, K. M., \& Nyland, H. I. (2000). Performance of the SF-36, SF12, and RAND-36 summary scales in a multiple sclerosis population. Medical Care., 38, 1022-1028.

Paltamaa, J., Sarasoja, T., Leskinen, E., Wikstrom, J., \& Malkia, E. (2008). Measuring deterioration in International Classification of Functioning domains of people with multiple sclerosis who are ambulatory. Physical Therapy, 88, 176-190.

Paluck, E. C., Allerdings, M., Kealy, K., \& Dorgan, H. (2006). Health promotion needs of women living in rural areas: an exploratory study. Canadian Journal of Rural Medicine, $11,111-116$. 
Peters, T., Somerset, M., Campbell, R., \& Sharp, D. (2003). Variables associated with attendance at, and the perceived helpfulness of, meetings for people with Multiple Sclerosis. Health and Social Care in the Community, 11, 19-26.

Rimmer, J. H., Wang, E., \& Smith, D. (2008). Barriers associated with exercise and community access for individuals with stroke. Journal of Rehabilitation Research \& Development, 45, 315-322.

Schriner, K. F. \& Fawcett, S. B. (1988). Development and validation of the community concerns report method. Journal of Community Psychology, 16, 306-316.

Stang, I. \& Mittelmark, M. B. (2010). Intervention to enhance empowerment in breast cancer self-help groups. Nursing Inquiry, 17, 46-56.

Stevens, M. J. \& Duttlinger, J. (1998). Correlates of participation in a breast cancer support group. Journal of Psychosomatic Research, 48, 263-275.

Uccelli, M. M., Mohr, L. M., Battalia, M. A., Zagami, P., \& Mohr, D. C. (2004). Peer support groups in multiple sclerosis: Current effectiveness and future directions. Multiple Sclerosis, 10, 80-84.

VandenBos, G. R. (2007). APA dictionary of psychology. Washington DC: American Psychological Association.

Walch, S. E., Roetzer, M. L., \& Minnett, T. A. (2006). Support group participation among persons with HIV: Demographic characteristics and perceived barriers. IDAS Care, 18, 284-289.

Wiebe, J., Finlayson, M., \& Payne, L. (1998). Social Action and IFS Survey Results: Atlantic Division. Toronto, ON: Multiple Sclerosis Society of Canada. 
TABLE 1: Descriptive characteristics of participants by time since last MS support group attendance (N=1275).

\begin{tabular}{|c|c|c|c|c|c|c|c|c|c|}
\hline \multirow[b]{4}{*}{ Characteristics } & \multicolumn{8}{|c|}{ Last Used Support Group Services $(N=1275)$} & \multirow[b]{4}{*}{$P$-value } \\
\hline & \multirow{2}{*}{\multicolumn{2}{|c|}{$\begin{array}{c}\text { Never Attend } \\
(n=451)\end{array}$}} & \multirow{2}{*}{\multicolumn{2}{|c|}{$\begin{array}{l}>3 \text { Years } \\
(n=327)\end{array}$}} & \multirow{2}{*}{\multicolumn{2}{|c|}{$\begin{array}{l}1 \text { to } 3 \text { Years } \\
(n=108)\end{array}$}} & \multirow{2}{*}{\multicolumn{2}{|c|}{$\begin{array}{c}<1 \text { Year } \\
(n=389)\end{array}$}} & \\
\hline & & & & & & & & & \\
\hline & $n$ & Row \% & $n$ & Row \% & $n$ & Row \% & $n$ & Row \% & \\
\hline \multicolumn{10}{|l|}{ Sex } \\
\hline Male & 128 & 38.10 & 74 & 22.02 & 29 & 8.63 & 105 & 31.25 & \\
\hline Female & 323 & 33.30 & 284 & 29.28 & 79 & 8.14 & 284 & 29.28 & 0.3357 \\
\hline \multicolumn{10}{|l|}{ Education } \\
\hline High School or Less & 142 & 36.04 & 108 & 27.41 & 31 & 7.87 & 113 & 28.68 & \\
\hline More Than High School & 309 & 35.07 & 219 & 24.86 & 77 & 8.74 & 276 & 31.33 & 0.6517 \\
\hline \multicolumn{10}{|l|}{ Means of Transportation } \\
\hline Drive Self & 229 & 36.06 & 155 & 24.41 & 48 & 7.56 & 203 & 31.97 & \\
\hline $\begin{array}{l}\text { Informal [ Family or Friends Drive] } \\
\text { Formal [ Public, Taxi, Disability }\end{array}$ & 173 & 33.72 & 134 & 26.12 & 47 & 9.16 & 159 & 30.99 & \\
\hline $\begin{array}{l}\text { Transit] } \\
\text { Type of Community }\end{array}$ & 38 & 35.85 & 33 & 31.13 & 12 & 11.32 & 23 & 21.70 & 0.3044 \\
\hline Primarily Urban or Suburban & 259 & 38.26 & 169 & 24.96 & 61 & 9.01 & 188 & 27.77 & \\
\hline $\begin{array}{l}\text { Small Town or Rural } \\
\text { Marital Status }\end{array}$ & \multicolumn{8}{|c|}{ Marital Status } & 0.0518 \\
\hline Married & 303 & 31.17 & 213 & 21.91 & 76 & 7.82 & 380 & 39.09 & \\
\hline Not Married & 148 & 36.82 & 113 & 28.11 & 32 & 7.96 & 109 & 27.11 & 0.2382 \\
\hline \multicolumn{10}{|l|}{ Presence of a Helper } \\
\hline No & 10 & 33.33 & 8 & 26.67 & 3 & 10.00 & 9 & 30.00 & \\
\hline Yes & 441 & 35.42 & 319 & 25.62 & 105 & 8.43 & 380 & 30.52 & 0.9872 \\
\hline \multicolumn{10}{|l|}{ Degree of Symptoms Interference } \\
\hline Very Minimal & 123 & 42.56 & 61 & 21.11 & 15 & 5.19 & 90 & 31.14 & \\
\hline Minimal & 113 & 36.57 & 77 & 24.92 & 22 & 7.12 & 97 & 31.39 & \\
\hline Moderate & 86 & 34.26 & 63 & 25.10 & 20 & 7.97 & 82 & 32.67 & \\
\hline Severe & 104 & 29.63 & 102 & 29.06 & 44 & 12.54 & 101 & 28.77 & 0.0046 \\
\hline \multicolumn{10}{|l|}{ Degree of ADL Limitations } \\
\hline None & 129 & 45.42 & 65 & 22.89 & 14 & 4.93 & 76 & 26.76 & \\
\hline Minimal & 105 & 35.12 & 66 & 22.07 & 23 & 7.69 & 105 & 35.12 & \\
\hline Moderate & 114 & 30.98 & 92 & 25.00 & 38 & 10.33 & 124 & 33.70 & \\
\hline Maximal & 100 & 31.65 & 103 & 32.59 & 32 & 10.13 & 81 & 25.63 & $<.0001$ \\
\hline
\end{tabular}


Degree of IADL Limitations

Very Minimal

Minimal

Moderate

Maximal

MS Status Within the past Year

Stable

Improving

Deteriorating

Variable

Do You Live Alone?

Live Alone

Live With Others

Age of Person with MS

Years Since Diagnosis

Number of Household Members

\begin{tabular}{|c|c|c|c|c|c|c|c|c|}
\hline 131 & 47.29 & 67 & 24.19 & 13 & 4.69 & 66 & 23.83 & \\
\hline 115 & 32.49 & 77 & 21.75 & 30 & 8.47 & 132 & 37.29 & \\
\hline 102 & 31.68 & 76 & 23.60 & 31 & 9.63 & 113 & 35.09 & \\
\hline 95 & 31.15 & 102 & 33.44 & 32 & 10.49 & 76 & 24.92 & $<.0001$ \\
\hline 192 & 36.43 & 126 & 23.91 & 39 & 7.40 & 170 & 32.26 & \\
\hline 11 & 25.58 & 11 & 25.58 & 1 & 2.33 & 20 & 46.51 & \\
\hline 146 & 33.72 & 123 & 28.41 & 43 & 9.93 & 121 & 27.94 & \\
\hline 100 & 37.45 & 66 & 24.72 & 24 & 8.99 & 77 & 28.84 & 0.1573 \\
\hline 102 & 36.43 & 84 & 30.00 & 24 & 8.57 & 70 & 25.00 & \\
\hline 349 & 35.11 & 242 & 24.35 & 84 & 8.45 & 319 & 32.09 & 0.0921 \\
\hline mean & std & mean & std & mean & std & mean & $s t d$ & P-value \\
\hline 64.26 & 9.76 & 64.54 & 8.94 & 64.46 & 9.54 & 62.46 & 9.11 & 0.0089 \\
\hline 20.36 & 12.72 & 23.19 & 10.47 & 18.28 & 10.52 & 17.56 & 10.41 & $<.0001$ \\
\hline 1.03 & 0.91 & 1.05 & 1.01 & 1.06 & 0.93 & 1.07 & 0.84 & 0.9087 \\
\hline
\end{tabular}


TABLE 2: Results from Multinomial Regression Modeling How Recently a MS Support Group Had Been Attended

\begin{tabular}{|c|c|c|c|c|c|c|c|c|}
\hline \multirow[b]{2}{*}{ Effect } & \multirow{2}{*}{$\begin{array}{l}\text { Response Level (Ref: Never } \\
\text { Attended Support Group) }\end{array}$} & \multirow[b]{2}{*}{$D F$} & \multirow[b]{2}{*}{ Estimate } & \multirow[b]{2}{*}{$S E$} & \multirow[b]{2}{*}{ OR } & \multicolumn{2}{|c|}{$95 \%$ CI for $O R$} & \multirow[b]{2}{*}{ P-value } \\
\hline & & & & & & $L C L$ & $U C L$ & \\
\hline \multicolumn{9}{|l|}{ Intercept } \\
\hline & More Than 3 Years Ago & 1 & -0.0765 & 0.5241 & & & & 0.1447 \\
\hline & 1 to 3 Years Ago & 1 & -2.0347 & 0.0793 & & & & 0.0103 \\
\hline & Within The Past Year & 1 & 0.7602 & 0.4930 & & & & 0.1230 \\
\hline \multirow[t]{4}{*}{ Age } & & 3 & & & & & & 0.0020 \\
\hline & More Than 3 Years Ago & 1 & -0.0002 & 0.0081 & 1.00 & 0.98 & 1.02 & 0.9847 \\
\hline & 1 to 3 Years Ago & 1 & -0.0045 & 0.0119 & 1.00 & 0.97 & 1.02 & 0.7071 \\
\hline & Within The Past Year & 1 & -0.0266 & 0.0077 & 0.97 & 0.96 & 0.99 & 0.0006 \\
\hline \multicolumn{2}{|c|}{ Type of Community (REF: Primarily Urban or Suburban) } & 3 & & & & & & 0.0505 \\
\hline \multirow{3}{*}{$\begin{array}{l}\text { Small Town or } \\
\text { Rural }\end{array}$} & More Than 3 Years Ago & 1 & 0.2286 & 0.1489 & 1.26 & 0.94 & 1.68 & 0.1248 \\
\hline & 1 to 3 Years Ago & 1 & 0.0031 & 0.2206 & 1.00 & 0.65 & 1.55 & 0.9887 \\
\hline & Within The Past Year & 1 & 0.3702 & 0.1424 & 1.45 & 1.10 & 1.91 & 0.0093 \\
\hline \multicolumn{2}{|c|}{ IADL Limitations (REF: Very Minimal Limitations) } & 9 & & & & & & $<.0001$ \\
\hline \multirow{3}{*}{$\begin{array}{l}\text { Maximal } \\
\text { Limitation }\end{array}$} & More Than 3 Years Ago & 1 & 0.7389 & 0.2100 & 2.09 & 1.39 & 3.16 & 0.0004 \\
\hline & 1 to 3 Years Ago & 1 & 1.2585 & 0.3582 & 3.49 & 1.73 & 7.03 & 0.0005 \\
\hline & Within The Past Year & 1 & 0.5768 & 0.2194 & 1.78 & 1.16 & 2.74 & 0.0086 \\
\hline \multirow{3}{*}{$\begin{array}{l}\text { Moderate } \\
\text { Limitation }\end{array}$} & More Than 3 Years Ago & 1 & 0.2717 & 0.2114 & 1.31 & 0.87 & 1.99 & 0.1987 \\
\hline & 1 to 3 Years Ago & 1 & 0.9845 & 0.3569 & 2.68 & 1.33 & 5.39 & 0.0058 \\
\hline & Within The Past Year & 1 & 0.8791 & 0.2003 & 2.41 & 1.63 & 3.57 & $<.0001$ \\
\hline \multirow{3}{*}{$\begin{array}{l}\text { Minimal } \\
\text { Limitation }\end{array}$} & More Than 3 Years Ago & 1 & 0.3643 & 0.2161 & 1.44 & 0.94 & 2.20 & 0.0918 \\
\hline & 1 to 3 Years Ago & 1 & 1.1363 & 0.3588 & 3.12 & 1.54 & 6.29 & 0.0015 \\
\hline & Within The Past Year & 1 & 0.8820 & 0.2078 & 2.42 & 1.61 & 3.63 & $<.0001$ \\
\hline
\end{tabular}

Note 1. For multinomial models, there are $n-1$ number of intercepts and parameter estimates for each level of an effect, where $n$ indicates the number of levels in the outcome variable.

Note 2. Estimates and odds ratios for comparisons other than the reference category can be obtained by a simple subtraction of 2 estimates. For example, considering the independent variable of type of community, one can compare individuals who have attended a support group within the past year with those who attended 1 to 3 years ago is $0.3702-0.0031=0.3661$ with an odds ratio of $\exp (0.3661)=1.44$.

Note 3. REF = reference group. 
TABLE 3: Results from Logistic Regression Modeling Unmet Need for MS Support Group

\begin{tabular}{|c|c|c|c|c|c|c|c|}
\hline \multirow[b]{2}{*}{ Effect } & \multirow[b]{2}{*}{ DF } & \multirow[b]{2}{*}{ Estimate } & \multirow[b]{2}{*}{ SE } & \multirow[b]{2}{*}{ OR } & \multicolumn{2}{|c|}{ 95\% CI for OR } & \multirow[b]{2}{*}{ P-value } \\
\hline & & & & & LCL & UCL & \\
\hline Intercept & 1 & -2.3859 & 0.2848 & & & & $<.0001$ \\
\hline Sex (Ref: Male) & 1 & 0.4446 & 0.1892 & 1.56 & 1.08 & 2.26 & 0.0188 \\
\hline Education (Ref: High School or Less) & 1 & -0.2850 & 0.1613 & 0.75 & 0.55 & 1.03 & 0.0773 \\
\hline Presence of Helper (Ref: Yes) & 1 & 1.2199 & 0.4405 & 3.39 & 1.43 & 8.03 & 0.0056 \\
\hline Symptoms Interference (REF: Very Minimal) & 3 & & & & & & $<.0001$ \\
\hline Severe & 1 & 0.5887 & 0.2540 & 1.80 & 1.10 & 2.96 & 0.0205 \\
\hline Moderate & 1 & 0.5987 & 0.2633 & 1.82 & 1.09 & 3.05 & 0.0230 \\
\hline Minimal & 1 & 1.2559 & 0.2340 & 3.51 & 2.22 & 5.55 & $<.0001$ \\
\hline
\end{tabular}

Note. $\mathrm{REF}=$ reference group. 
Figure 1: Flow Diagram used to define “Unmet Needs” for MS Support Group Services $(\mathrm{N}=1275)$.

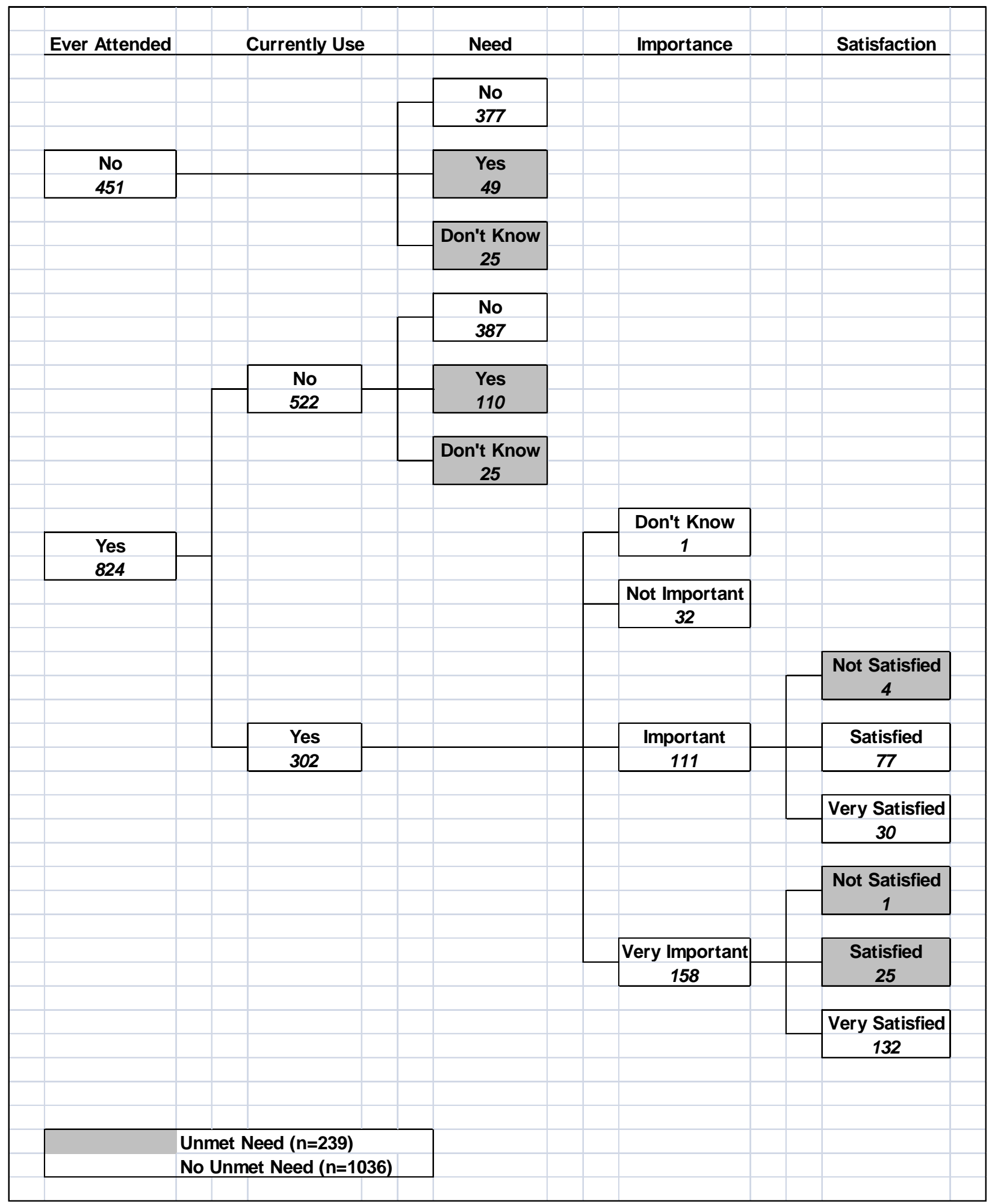

